\title{
EFFICIENCY OF PREY SUBJUGATION BY ONE SPECIES OF Myrmeleon LARVAE (NEUROPETRA: MYRMELEONTIDAE) IN THE CENTRAL AMAZONIA
}

\author{
DIAS, S. C. ${ }^{1}$, SANTOS, B. A. ${ }^{2}$, WERNECK, F. P. ${ }^{3}$, LIRA, P. K. ${ }^{4}$, \\ CARRASCO-CARBADILLO, V. ${ }^{5}$ and FERNANDES, G. W. ${ }^{6}$ \\ ${ }^{1}$ Museu Paraense Emílio Goeldi, Laboratório de Aracnologia, Av. Perimetral, 1901, Terra Firme, \\ C. P. 399, CEP 66017-970, Belém, PA, Brazil \\ ${ }^{2}$ Coordenação de Pesquisas em Silvicultura Tropical, Instituto Nacional de Pesquisas da Amazônia (INPA), \\ C. P. 478, CEP 69011-970, Manaus, AM, Brazil \\ ${ }^{3}$ Departamento de Ecologia, Universidade de Brasília, UnB, CEP 70910-900, Brazil \\ ${ }^{4}$ Universidade Federal do Rio de Janeiro, Instituto de Biologia, Depto. de Ecologia, CEP 21941-590, \\ Rio de Janeiro, RJ, Brazil \\ ${ }^{5}$ Restauración Ecológica, Depto. Sistemática Molecular y Evolución, CEAMISH, UAEM, Av. Universidad, 1001, \\ C. P. 62210, Col. Chamilpa Cuernavaca, Morelos, México \\ ${ }^{6}$ Ecologia Evolutiva \& Biodiversidade, ICB, Universidade Federal de Minas Gerais, C. P. 486, \\ CEP 301161-970, Belo Horizonte, MG, Brazil \\ Correspondence to: Sidclay C. Dias, Museu Paraense Emílio Goeldi, Laboratório de Aracnologia, Av. Perimetral, 1901, \\ Terra Firme, C. P. 399, CEP 66017-970, Belém, PA, Brazil, e-mail: pachistopelma@ hotmail.com \\ Received October 29, 2004 - Accepted January 13, 2005 - Distributed May 31, 2006
}

(With 1 figure)

Myrmeleontidae larvae are known as ant lions and pit-making inverted funnels in order to catch their prey, which is generally ants and other soil arthropods (Heinrich \& Heinrich, 1984). Ant lions present behavioral predation actions whose first movements are a quick attack followed by a hard pressure of the jaw against the victim until submergence in the sand (Napolitano, 1998). These first behavioral movements involve the time of prey subjugation. Funnel traps are preferentially built in places with sand soils and their spatial distribution is dependent on both larvae density and substrate physic conditions (McClure, 1983; Gotelli, 1993).

Positive correlation exists between larvae length and funnel diameter in an optimum substrate (Allen \& Croft, 1985; Lopes de Faria et al., 1994). As the animal grows, it needs more energy, which must be obtained by consuming larger or more numerous prey. In theory, the increase in funnel diameter enhances the efficiency of prey catch, as larger traps increase the fall probability of more or larger prey (Heinrich \& Heinrich, 1984; Day $\&$ Zalucki, 2000). The aim of our study is to test how these two factors (larvae length and funnel diameter) affect the efficiency of prey subjugation.

The study was carried out in July, 2004 at the $41 \mathrm{~km}$ Reserve $\left(02^{\circ} 24^{\prime} \mathrm{S}\right.$ and $\left.59^{\circ} 52^{\prime} \mathrm{W}\right)$ belonging to the Biological Dynamics of the Forest Fragments Project (INPA/ SI), located $80 \mathrm{~km}$ near Manaus, AM. We offered Crematogaster sp. ants (medium length $2 \mathrm{~mm}$ ) to each resident larvae of Myrmeleon in 22 funnels with different diameters and measured the time of prey subjugation. Before offering, we measured the funnel diameter by using a caliper. After the subjugation, we collected the larvae and measured their length from the anterior border of the clypeus to the final portion of the abdomen. We considered subjugated prey as that captured and wholly or partially buried (only the head unburied) by the ant lion larvae. We tested possible relationships between i) larvae length and funnel diameter; ii) time of prey subjugation and funnel diameter; and iii) time of prey subjugation and larvae length using the Spearman correlation coefficient $(\alpha=0.05)$.

Funnel traps presented a large diameter range (9-64 mm; median $32.5 \mathrm{~mm}$ ). 22 larvae collected showed lengths ranging from 2 to $9 \mathrm{~mm}$ (median $6 \mathrm{~mm}$ ). The time of prey subjugation varied from 12 to 240 seconds (median $79 \mathrm{~s}$ ). The larvae length and funnel diameter were positively correlated $(r s=0.72 ; \mathrm{p}<0.001)$. No correlation between the funnel diameter and time of prey subjugation was observed $(r s=-0.11 ; \mathrm{p}=0.61$; Fig. 1a), however the larvae length and time of prey subjugation 


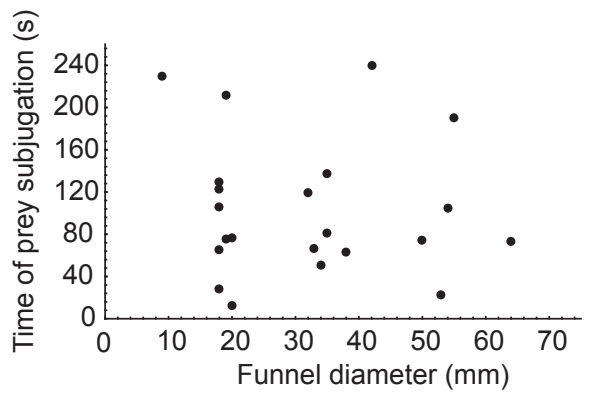

(a)

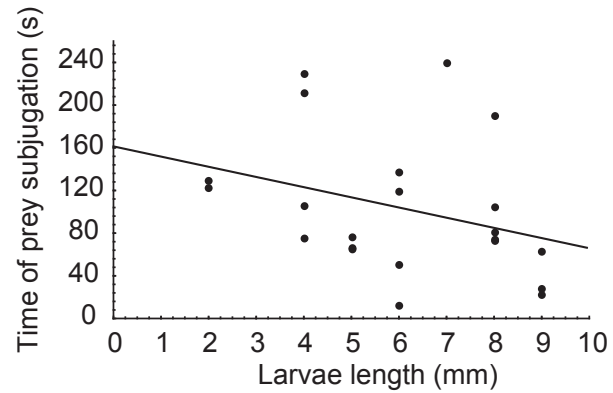

(b)

Fig. 1 - a) Plot of time of prey subjugation by ant lion vs. funnel diameter in the $41 \mathrm{~km}$ Reserve, Manaus, AM; and b) Relationship between ant lion larvae length and time of prey subjugation in the $41 \mathrm{~km}$ Reserve, Manaus, AM.

correlated negatively $(r s=-0.439 ; \mathrm{p}=0.04$; Fig. 1b).

The larvae length and funnel diameter are described in the literature as variables which are strongly related (Allen \& Croft, 1985; Lopes de Faria et al., 1994). Our results not only corroborated this tendency, but also stress the fact that some large larvae have inhabited small funnels. We hypothesize two possible explanations supporting this issue: competition for suitable sites to funnel building and prey availability. Allen \& Croft (1985) and Day \& Zalucki (2000), who studied spatial competition among ant lions, showed that enlarging in larvae spatial density might imply a reduction in the funnel diameter, forcing large larvae to build little funnels. Day \& Zalucki (2000), who studied prey abundance, showed experimentally that after starvation periods, the ant lion larvae do not grow their funnels or create new ones. However Pes et al. (2002) showed in the $41 \mathrm{~km}$ reserve that there was no relationship between prey availability and funnel diameter. Once Crematogaster sp. ants are very abundant in our study site, space competition seems to be the most plausible explanation for why some large larvae build little funnels. Although we have not tested it, we observed an aggregate pattern of funnel spatial distribution in the study area restricted to suitable soil substrates which were not exposed to rainfall.

Our result regarding no significant correlation between funnel diameter and time of prey subjugation indicate that, for the prey length that we offered, the larger larvae show higher catch efficiency (Lopes de Faria et al., 1994), independently of the funnel diameter. To conclude, large larvae could be building little funnels due to spatial competition, suggesting that larvae length is a more determining factor than funnel diameter in the efficiency of prey subjugation.
Acknowledgments - To BDFFP (INPA/SI) for the opportunity of the field course "Ecologia da Floresta Amazônica 2004"; to Glauco Machado (UNICAMP) and Paulo de Marco Jr. (UFV) for initial drafts of the manuscript; to CAPES and CNPq for M.Sc grants and scholarships to the following authors (BAS, FPW and PKL); GWF received a grant from $\mathrm{CNPq}$; to $\mathrm{CNPq}$ for PhD grant scholarship to SCD.

\section{REFERENCES}

ALLEN, G. R. \& CROFT, D. B., 1985, Soil particle size and the pit morphology of the Australian ant-lions Myrmeleon diminutus and M. pictifrons (Neuroptera: Myermelontidae). Aust. J. Zool., 33: 863-874.

DAY, M. D. \& ZALUCKI, M. P., 2000, Effect of density on spatial distribution, pit formation and pit diameter of Myrmeleon acer Walker, (Neuroptera: Myrmeleontidae): patterns and processes. Aust. Ecol., 25: 58-64.

GOTELLI, N. J., 1993, Ant lion zones: causes of high-density predator aggregations. Ecology, 74: 226-237.

HEINRICH, B. \& HEINRICH, M. J. E., 1984, The pit-trapping foraging strategy of the ant lion, Myrmeleon immaculatus DeGeer (Neuroptera: Myrmeleontidae). Behav. Ecol. Sociobiol., 14: 151-160.

LOPES DE FARIA, M., PRADO, P. I. L., BEDE, L. C. \& FERNANDES, G. W., 1994, Estrutura e dinâmica de uma população de larvas de Myrmeleon uniformis (Neuropoptera: Myrmeleontidae). Rev. Brasil. Biol., 54: 335-344.

MCCLURE, M. S., 1983, Myrmeleon(Hormiga León, Antlions), pp. 742-743. In: D. H. Janzen (eds.), Costa Rican Natural History, 816 p., The University of Chicago Press, London.

NAPOLITANO, J. F., 1998, Predatory behavior of a pit-making antlion, Myrmelon mobilis (Neuroptera: Myrmeleontidae). Fla. Entomol., 81: 562-566.

PES, A. M. O., PIMENTEL, F., JORGE, M. L., VEIGA, M. C. \& HIDALGO, M., 2002, Larvas de formigas-leão (Myrmeleontidae, Neuroptera) famintas aumentam o esforço de captura?, pp. 53-55. In: E. Venticinque \& J. Zuanon (eds.), Ecologia da Floresta Amazônica - Livro do Curso de campo, 122 p., INPA/PDBFF, Manaus. 